\title{
RASIO SOLVABILITAS DAN RENTABILITAS PADA LAPORAN KEUANGAN PT. BANK PERKREDITAN RAKYAT CINCIN PERMATA ANDALAS CABANG PADANG (BPR CPA)
}

\author{
Diki Fernando.D, Elva Dona \\ Akademi Keuangan Dan Perbankan "Pembangunan" Padang \\ Dikifernando2623@gmail.com
}

\begin{abstract}
This research is concerned to analyze and determine the level of bank health by using the Solvency Ratio and Profitability Ratio at PT. BPR Ring Permata Andalas Padang branch to find out about funding for bank assets and profits in the financial statements. The data used is taken from the balance sheet of PT. BPR Ring Permata Andalas Padang branch. The results of this study are not good because the Solvability Ratio is not healthy and Rentability fluctuates every year.
\end{abstract}

Keywords: Bank, Solvency Ratio, Profitability

\section{PENDAHULUAN}

Bank berkembang sangat pesat dalam dampak pertumbuhan perekonomian dalam lingkungan masyarakat, sehingga terjadinya persaingan yang ketat dalam dunia perbankan dan bersaing untuk mendapatkan simpati dari masyarakat menjadi nasabah bank. Berbagai produk telah dikeluarkan bank dengan menyediakan berbagai fasilitas dan memberikan kemudahan bertujuan untuk menarik simpati masyarakat banyak menjadi nasabah dan menggunakan fasilitas yang telah disediakan oleh pihak bank tersebut. Masyarakat dalam menentukan jasa perbankan sesuai dengan yang diperlukan calon nasabah dan produk jasa yang ada di bank tersebut karena semakin banyak calon nasabah yang mengerti manfaat dan fungsi dari bank sebagai tempat penyimpanan atau tempat melakukan transaksi keuangan sehingga masyarakat atau calon nasabah akan lebih memilih bank secara selektif.

Sekarang banyak bank BPR (Bank Perkreditan Rakyat) dimasyarakat yang bersaing untuk memberikan beberapa kemudahan untuk masyarakat dalam melakukan penyimpanan atau pinjaman. Dalam memberikan jasanya perusahaan mempertimbangkan beberapa aspek diantaranya terdapat berbagai prosedur yang harus dilengkapi oleh setiap calon nasabah.

Perkembangan jaman yang diikuti dengan perkembangan perekonomian menuntut seluruh masyarakat untuk berkarya dan lebih baik. Lembaga keuangan baik pemerintah maupun swasta juga dituntut agar bisa memberikan pelayanan dan ikut membantu masyarakat menghadapi perkembangan jaman tersebut.

Bank sebagai lembaga keuangan mempunyai peranan yang sangat penting dalam kehidupan masyarakat yang semakin maju yaitu sebagai penggerak perekonomian. Unit-unit ekonomi yang mengalami kelebihan dana dapat 
menyalurkan dananya ke unit-unit ekonomi yang mengalami kekurangan dana melalui bank. Bank Perkreditan Rakyat sebagai salah satu jenis bank di Indonesia yang mempunyai ruang lingkup yang lebih kecil dari bank umum ditujukan untuk mempermudah masyarakat di daerah untuk mendapatkan dana dalam mengembangkan usahanya.

Salah satu Bank Perkreditan Rakyat di Indonesia adalah PT. BPR Cincin Permata Andalas. Agar dapat melaksanakan tugas pokok dan mempertahankan kelangsungan usaha dari bank tersebut, kepercayaan dari masyarakat pada bank sangat penting. Untuk menjaga kepercayaan dari masyarakat, pengelola bank dalam menjalankan kegiatan usahanya harus senantiasa menjaga keseimbangan antara pemeliharaan likuiditas yang cukup dan pencapaian rentabilitas yang wajar serta pemenuhan kebutuhan modal yang memadai sesuai dengan jenis penanamannya.

Di samping itu, bank juga mengumumkan posisi keuangannya pada periode-periode tertentu agar masyarakat dapat mengetahui posisi keuangan dari bank tersebut. Kemajuan dan kemunduran suatu bank dalam suatu periode tertentu dapat diketahui dari berbagai aktivitasnya dan dari kondisi keuangannya. Kondisi keuangan suatu bank dapat diketahui dari penyusunan laporan keuangan bank yang bersangkutan dengan menghubungkan elemen-elemen dari berbagai aktiva dan pasiva dalam neraca pada suatu periode tertentu.

Gambaran mengenai perkembangan suatu bank dapat diperoleh dengan mengadakan analisis terhadap data keuangan. Neraca mencerminkan nilai aktiva, hutang, dan modal pada waktu tertentu, sedangkan Laporan Laba/Rugi mencerminkan hasil usaha yang telah dicapai selama periode tertentu. Mengadakan analisis terhadap laporan keuangan suatu bank akan bermanfaat untuk mengetahui keadaan serta perkembangan finansial maupun hasil-hasil yang telah dicapai pada waktu yang lalu dan waktu yang sedang berjalan.

Tingkat kesehatan pada PT. BPR Cincin Permata Andalas Cabang Padang dapat dilihat didalam laporan keuangan dengan beberapa metode analisa yaitu dengan menggunakan Rasio Solvabilitas dan Rasio rentabilitas dengan periode waktu 2016 sampai tahun 2018.

Dengan mengadakan analisis data keuangan dari tahun ke tahun dapat diketahui kelemahan-kelemahan dari bank tersebut serta hasil-hasil yang baik maupun dianggap baik. Hasil analisis sangat penting artinya bagi perbaikan penyusunan rencana kerja ditahun-tahun yang akan datang dengan memperbaiki kelemahan-kelemahan yang dapat ditemukan dari hasil analisis tersebut.

Rasio solvabilitas dapat memberikan informasi apakah modal bank cukup untuk mendukung operasi bank dan mampu menyerap kerugian-kerugian bank yang terjadi dalam penanaman dana atau penurunan aktiva. Rasio rentabilitas digunakan untuk mengukur efektivitas bank untuk memperoleh laba. Dengan menggunakan analisis rasio solvabilitas, dan rentabilitas dapat diketahui kinerja keuangan pada PT. BPR Cincin Permata Andalas pada periode 2016 - 2018.

Kebijaksanaan bank, termasuk perkreditan, tidak dapat disamaratakan antara satu bank dengan bank yang lain. Setiap bank mengatur pencapaian keseluruhan sasaran dantujuan kegiatan usahanya. M. Taufiq (2010) 
Berdasarkan uraian diatas, maka penulis mengambil judul "Rasio Solvabilitas Dan Rentabilitas Pada Laporan Keuangan PT. Bank Perkreditan Rakyat Cincin Permata Andalas Cabang Padang (BPR CPA)".

\section{METODE PENELITIAN}

1. Metode Pengumpulan Data

a. Dokumentasi

Pengumpulan data dilakukan dengan cara wawancara langsung dengan responden sesuai dengan tujuan penelitian.

b. Studi Kepustaka (Library Research)

Studi perpustakaan dilakukan untuk memperoleh tulisan-tulisan dan informasi yang berhubungan dengan pembahasan yang dilakukan.

2. Metode Analisa Data

Dalam menganalisa data, penulis menggunakan metode analisa data deskriptif metode penelitian yang menjelaskan secara tepat tentang kesehatan keuangan pada PT. Bank Perkreditan Rakyat Cincin Permata Andalas Cabang Padang.

\section{HASIL DAN PEMBAHASAN}

Solvabilitas adalah menggambarkan kemampuan perusahaan dalam membayar kewajiban jangka panjang maupun kewajiban-kewajibannya yang apabila perusahaan dilikuidasi. Ratio ini dapat dihitung dari pos-pos atau sifatnya jangka panjang seperti aktiva tetap utang jangka panjang. Dengan kriteria rasio solvabilitas seusai aturan yang terdapat pada undang-undang No. 3/21/PBI/2001 Tanggal 13 Desember 2001 tentang Kewajiban Penyediaan Modal Minimum Bank (Lembaga Negara Republik Indonesia Tahun 2001 Nomor 149, Tambahan Lembaga Negara Republik Indonesia Nomor 4158).

\section{Tabel 1}

Kriteria Rasio Solvabilitas

\begin{tabular}{|l|l|}
\hline \multicolumn{1}{|c|}{ Standar } & \multicolumn{1}{c|}{ Kriteria } \\
\hline$\leq 40 \%$ & Sehat \\
\hline$>50 \%-60 \%$ & Cukup Sehat \\
\hline$>70 \%-80 \%$ & Kurang Sehat \\
\hline$>90 \%-100 \%$ & Tidak Sehat \\
\hline$>100 \%$ & Sangat Tidak Sehat \\
\hline
\end{tabular}

Adapun yang termasuk ratio solvabilitas adalah sebagai berikut :

1) Total Debt to Total Asset Ratio ( Rasio Hutang terhadap Aktiva)

Rasio ini merupakan perbandingan antara total hutang (total debt) dengan total assets. Rasio hutang mengukur berapa persen aset perusahaan yang dibelanjai dengan hutang.

Rasio ini dapat dihitung dengan rumus yaitu:

Total Debt to Total Asset Ratio $=\frac{\text { Total Hutang }}{\text { Total Aktiva }} \times 100 \%$

2) Total Debt to Equity Ratio (Rasio Hutang terhadap Ekuitas) 
Merupakan perbandingan dari total hutang yang dimiliki perusahaan dengan modal sendiri (ekuitas). Artinya bagian dari setiap rupiah modal sendiri yang dijadikan jamiman untuk keseluruhan hutang perusahaan yang diatur dalam ( undang undang Bank Indonesia Pasal 14 ayat 1) tentang" Memiliki rasio Kewajiban Penyediaan Modal Minimum sama dengan $8 \%$ (delapan perseratus) atau lebih, memiliki rasio Giro Wajib Minimum dalam rupiah 5\% (lima perseratus) atau lebih yang ditujukan dengan angka kurang dari Rp.0,800 atau 8\% modal sendiri mampu menjadi jaminan keseluruhan hutang perusahaan tersebut sesuai dengan ketentuan Bank Indonesia.

Rasio ini dapat dihitung dengan rumus yaitu:

Total Debt to Equity Ratio = $\frac{\text { Total Hutang }}{\text { Modal Sendiri }} \times 100 \%$

Rasio rentabilitas adalah rasio yang sering digunakan untuk mengukur kemampuan dari suatu perusahaan dalam menghasilkan laba dalam waktu periode tertentu berdasarkan surat keputusan direksi Bank Indonesia No. 30/11/KEP/DIR. Tanggal 30 April 1997 (Rentabilitas didasarkan kepada rasio laba terhadap volume usaha dengan bobot $5 \%$ dan rasio biaya oprasional terhadap pendapatan oprasional bobot $5 \%$. Rumus umum yang sering digunakan adalah $\mathrm{L} / \mathrm{M}$, di mana $\mathrm{L}$ adalah laba yang dihasilkan dan $\mathrm{M}$ adalah modal yang dikeluarkan untuk menghasilkan laba. Rasio rentabilitas ini sangat berkaitan erat dengan kelangsungan hidup suatu perusahaan. Jika nilai rasionya bagus berarti perusahaan dalam keadaan sehat keuangannya. Bagian-bagian dari rasio rentabilitas yaitu :

1) Profit Margin (PM)

Rasio ini benar-benar menilai kemampuan perusahaan untuk memperoleh laba bersih pada tingkat penjualan tertentu yang terlihat langsung pada analisis common size pada laporan laba rugi yang tepatnya berada pada baris terakhir. Rasio ini juga menunjukkan kemampuan perusahaan dalam menekan biaya-biaya atau ukuran efisiensi pada periode tertentu sehingga perbedaan biaya dan beban dalam akuntansi akan terlihat Rumus : $\frac{\text { Laba Bersih }}{\text { Penjualan }} \times 100 \%$

2) Gross Profit Margin (GPM)

Gross Profit Margin atau Margin Laba Kotor yaitu perhitungan dengan membandingkan antara laba kotor perusahaan dengan tingkat penjualan yang dicapai dalam periode tertentu yang sama. Laba kotor yang dicapai ini berupa setiap rupiah penjualan. Nilai rasio yang semakin besar berarti kondisi keuangan perusahaan semakin baik. Kemampuan perusahaan dalam menghasilkan laba untuk menggantikan biaya tetap atau biaya operasi lainnya. Rumus Gross Profit Margin sebagai berikut.

Rumus : $\frac{\text { Laba Kotor }}{\text { Penjualan Bersih }} \times 100 \%$

3) Net Profit Margin (NPM)

Net Profit Margin atau Margin Laba Bersih yaitu perhitungan dengan membandingkan antara laba bersih yang dihasilkan perusahaan 
yang berasal dari penjualan terhadap efisiensi seluruh kegiatan seperti produksi, administrasi, pemasaran, pendanaan, penentuan harga dan manajemen pajak. Semakin tinggi rasio ini berarti kemampuan perusahaan untuk menghasilkan laba juga tinggi pada tingkat penjualan tertentu. Jika rasio bernilai rendah maka penjualan juga rendah berdasarkan tingkat biaya tertentu atau kemungkinan lainnya biaya yang dikeluarkan perusahaan terlalu tinggi untuk tingkat penjualan tertentu. Rumus Net Profit Margin sebagai berikut.

Rumus : $\frac{\text { Laba Bersih Setelah Pajak }}{\text { Penjualan Bersih }} \times 100 \%$

\section{Pembahasan}

Rasio Solvabilitas dan Rentabilitas Laporan Keuangan PT. BPR Cincin Permata Andalas Cabang Padang, data dapat dilihat pada tabel berikut :

\section{Tabel 2}

Rasio Solvabilitas dan Rentabilitas

PT. Bank Perkreditan Rakyat Cincin Permata Andalas Cabang Padang

Tahun 2016 - 2018

\begin{tabular}{|c|c|c|c|c|c|}
\hline \multirow{2}{*}{ Tahun } & \multicolumn{2}{|c|}{ Rasio Solvabilitas } & \multicolumn{3}{c|}{ Rasio Rentabilitas } \\
\cline { 2 - 6 } & $\begin{array}{c}\text { Debt To } \\
\text { Asset Ratio }\end{array}$ & $\begin{array}{c}\text { Debt To } \\
\text { Equity Ratio }\end{array}$ & $\begin{array}{c}\text { Profit } \\
\text { Margin } \\
(\mathrm{PM})\end{array}$ & $\begin{array}{c}\text { Gross Profit } \\
\text { Margin } \\
(\mathrm{GPM})\end{array}$ & $\begin{array}{c}\text { Net } \\
\text { Profit } \\
\text { Margin } \\
(\mathrm{NPM})\end{array}$ \\
\hline 2016 & $1,15 \%$ & $7,9 \%$ & $174,59 \%$ & $330,27 \%$ & $107,51 \%$ \\
\hline 2017 & $0,032 \%$ & $1,4 \%$ & $513,20 \%$ & $521,69 \%$ & $504,71 \%$ \\
\hline 2018 & $0,36 \%$ & $2,5 \%$ & $318,31 \%$ & $330,27 \%$ & $230,31 \%$ \\
\hline
\end{tabular}

Sumber: BPR CPA Cabang Padang, data diolah

Dari tabel diatas dapat dilihat hasil dari masing-masing rasio solvabilitas dan rentabilitas, berikut analisa dari hasil tabel diatas : 
Gambar 1

Perkembangan Rasio Solvabilitas Tahun 2016 - 2018

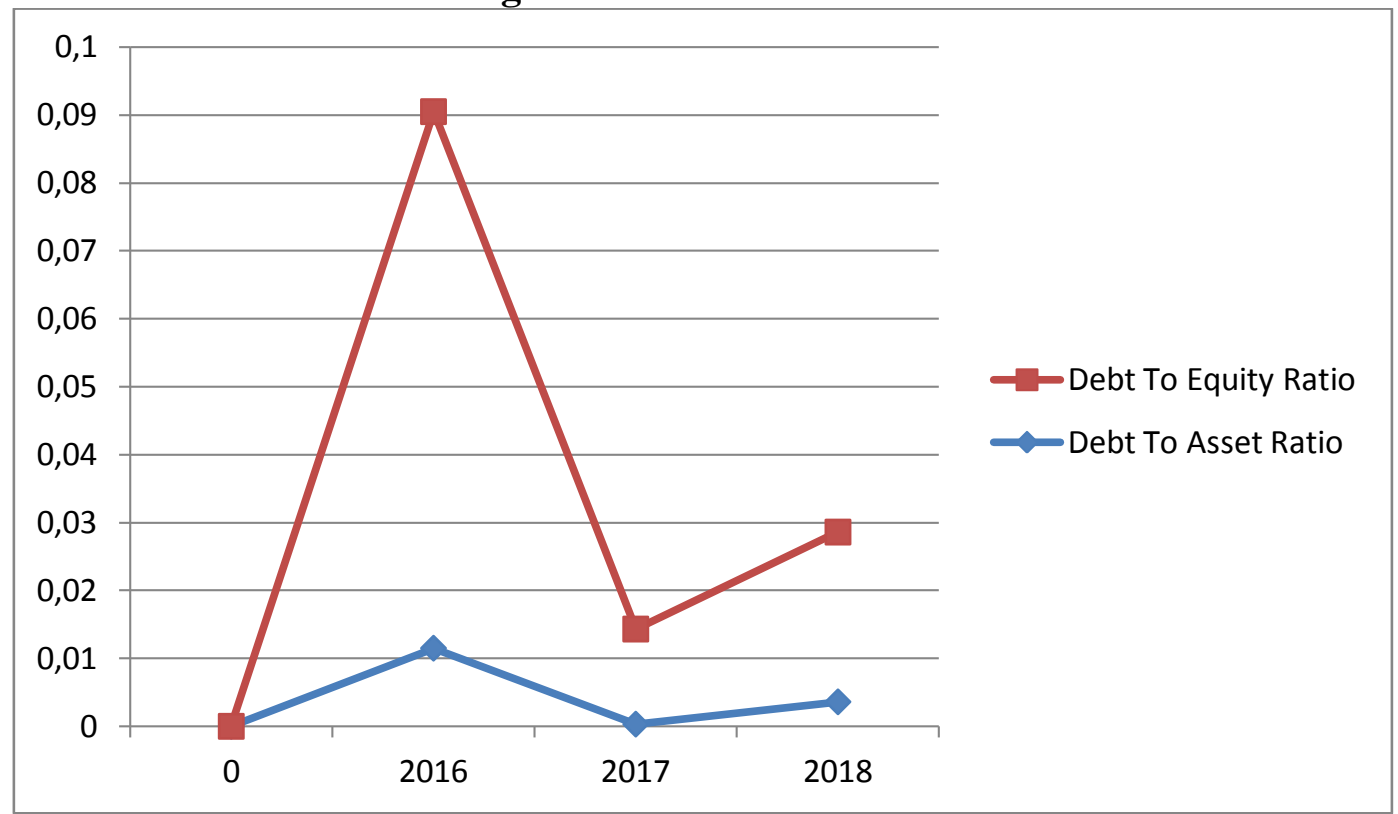

Dari tabel diatas terlihat perkembangan Debt To Asset Ratio tahun 2016 sampai 2017 menunjukkan penurunan sebesar 97,21\% dan pada tahun 2017 sampai 2018 mengalami peningkatan dengan nilai sebesar 1,02\%. Hal ini menunjukkan bahwa bank sehat karena menurut pada undang-undang No. 3/21/PBI/2001 Tanggal 13 Desember 2001 tentang Kewajiban Penyediaan Modal Minimum Bank (Lembaga Negara Republik Indonesia Tahun 2001 Nomor 149, Tambahan Lembaga Negara Republik Indonesia Nomor 4158)., bank yang dikategorikan sehat memiliki standar yaitu $\geq 40 \%$. Pernyataan ini menunjukkan bahwa bank mampu membayar hutang jangka panjangnya maupun kewajibankewajibannya.

Dilihat dari perkembangan debt tu equity ratio dari tahun 2016 sampai 2017 menunjukkan penurunan sebesar 82,27\% dan pada tahun 2017 sampai 2018 mengalami peningkatan yang cukup tinggi yaitu sebesar 78,57\% dimana menurut ( undang undang Bank Indonesia Pasal 14 ayat 1) tentang" Memiliki rasio Kewajiban Penyediaan Modal Minimum sama dengan 8\% (delapan perseratus) atau lebih, memiliki rasio Giro Wajib Minimum dalam rupiah 5\% (lima perseratus) bahwa bank dinyatakan sehat bila standar presentase nya sebesar $8 \% \%$ sedangkan bank yang dinyatakan kurang sehat berada di angka kurang dari $8 \%$. Pernyataan ini menunjukkan bahwa bank tidak mampu menjadikan setiap rupiah modal sendiri untuk keseluruhan hutang bank. 
Gambar 2

Perkembangan Rasio Rentabilitas Tahun 2016 - 2018

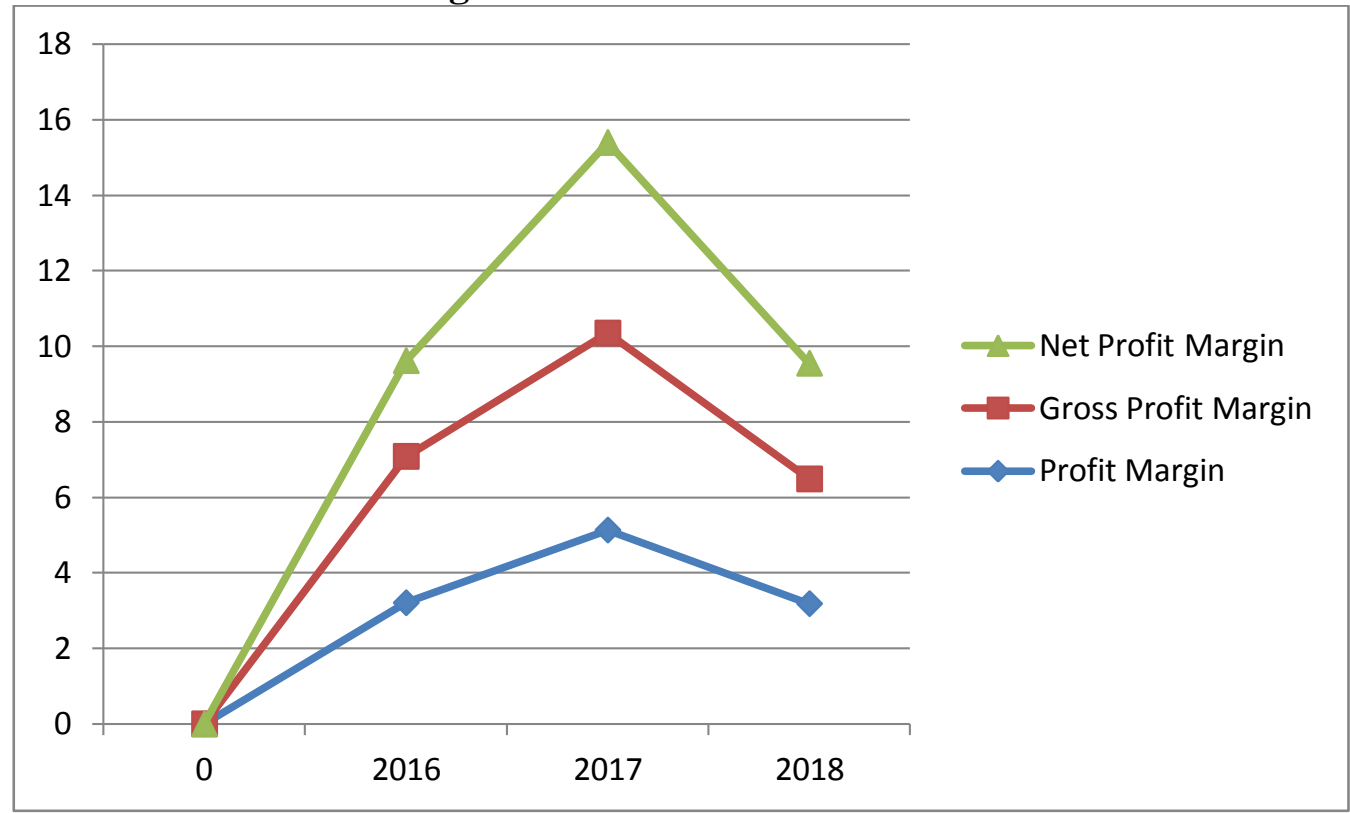

Pada tabel 3.2 diatas perkembangan nilai profit margin ditahun 2016 sampai 2017 menunjukkan nilai sebesar 60,05\% dan pada tahun 2017 sampai tahun 2018 mengalami penurunan yang sangat besar yaitu sebesar 37,53\%. Menurut surat edaran BI No. 30/11/KEP/DIR. Tanggal 30 April 1997 menyatakan bahwa bank dinyatakan sehat apabila bank tersebut memiliki standar presentase sebesar 5\%. Pernyataan ini menunjukkan bahwa PT. BPR Cincin Permata Andalas cabang Padang pada tahun 2017 sampai tahun 2018 dinyatakan tidak sehat.

Berdasarkan tabel 3.2 diatas perkembangan nilai gross profit margin pada tahun 2016 sampai tahun 2017 menunjukkan nilai sebesar 34,55\% dan pada tahun 2017 sampai tahun 2018 mengalami penurunan yang cukup besar yaitu sebesar 36,69\%. Menurut surat edaran BI No. 30/11/KEP/DIR. Tanggal 30 April 1997 bahwa bank dinyatakan sehat apabila bank tersebut berada pada standar presentase sebesar 5\% jika presentase dibawah 5\% berarti bank tersebut dinyatakan tidak sehat. Pernyataan ini menunjukkan bahwa pada tahun 2017 sampai tahun 2018 PT. BPR Cincin Permata Andalas dinyatakan tidak sehat.

Dilhat dari tabel diatas perkembangan nilai net profit margin pada tahun 2016 sampai tahun 2017 menunjukkan nilai sebesar 99,04\% dan pada tahun 2017 sampai tahun 2018 mengalami penurunan yang sangat besar yaitu sebesar 39,30\%. Menurut surat edaran BI No. 30/11/KEP/DIR. Tanggal 30 April 1997 bahwa bank dinyatakan sehat apabila bank tersebut berada pada standar presentase sebesar 5\% sedangkan pada pernyataan diatas menunjukkan bahwa pada tahun 2017 sampai tahun 2018 bank tersebut tidak mencapai standar presentase BI yang berarti bahwa bank tersebut dinyatakan tidak sehat.

PT. BPR Cincin Permata Andalas cabang Padang meliputi usahanya untuk menghimpun dana dan menyalurkan dana dengan tujuan mendapatkan keuntungan. Keuntungan BPR didapat dari pendapatan bunga, bunga tersebut 
didapat dari menjalin kerjasama dengan masyarakat sekitar PT. BPR atau yang termasuk rangkupan PT. BPR tersebut. PT. BPR Cincin Permata Andalas cabang Padang memulai program penyimpanan dan peminjaman di masyarakat sekitar BPR pada tahun 2007.

Kerjasama tersebut diwujudkan sesuai dengan kesepakatan kerja sama antar masyarakat dengan PT. BPR, antusias masyarakat dalam melakukan kerja sama dengan PT. BPR dikarenakan prosedur dan fasilitas yang ada pada bank tersebut tidak seperti bank umum dengan bunga peminjaman yang lebih rendah, dan PT. BPR tersebut juga melayani berbagai macam jenis kredit yang memudahkan masyarakat dalam membangun usahanya, contohnya PT. BPR meminjamkan dana nya pada nasabah dengan jaminan seperti kendaraan mobil angkot, motor atau lainnya yang dapat dijadikan jaminan, dana tersebut nantinya akan menjadi penambahan asset bagi peminjam dalam mengembangkan usahanya, didalam produknya PT. BPR juga melayani tabungan dengan fasilitas penjemputan di berbagai tempat dan penjemputan kredit, masyarakat yang selektif dalam mencari tempat penyimpanan atau peminjaman akan menganalisa tentang keuangan bank tersebut, pada tabel diatas sesuai analisa yang dilakukan PT. BPR Cincin Permata Andalas cabang Padang telah fluktuasi atau mengalami kurang sehat pada bagian solvabiltas dan mengalami laba naik pada tahun 2016 sampai 2017 dan turun pada tahun 2018.

\section{SIMPULAN}

Selama periode 2016 sampai 2018 PT. BPR Cincin Permata Andalas cabang Padang baik. Berdasarkan debt to asset ratio, yang ditunjukan dengan angka kurang dari $40 \%$ pendanaan hutang atas aktiva atau aset dapat dikatakan sehat, sedangkan batas minimum modal yang harus dimiliki bank menurut peraturan Bank Indonesia Nomor 3/21/PBI/2001 Tanggal 13 Desember 2001 tentang Kewajiban Penyediaan Modal Minimum Bank (Lembaga Negara Republik Indonesia Tahun 2001 Nomor 149, Tambahan Lembaga Negara Republik Indonesia Nomor 4158) adalah 40\% dari aktiva bank.

Berdasarkan debt to equity ratio selama tahun 2016 sampai tahun 2018, dapat dikategorikan tidak sehat karena yang tercantum dalam (undang undang Bank Indonesia Pasal 14 ayat 1) tentang” Memiliki rasio Kewajiban Penyediaan Modal Minimum sama dengan 8\% (delapan perseratus) atau lebih, memiliki rasio Giro Wajib Minimum dalam rupiah $5 \%$ (lima perseratus) atau lebih yang ditujukan dengan angka Rp.0,800 atau 8\% modal sendiri mampu menjadi jaminan keseluruhan hutang perusahaan tersebut sesuai dengan ketentuan Bank Indonesia.

Selama periode 2016 sampai 2018 kinerja keuangan PT. BPR Cincin Permata Andalas cabang Padang sudah baik, yang ditunjukan dengan profit margin, gross profit margin dan net profit margin yang cukup besar meskipun masih mengalami naik turun pada tiap tahunnya, hanya saja efektifitas manajemen bank dalam mengelola assetnya untuk menghasilkan laba naik dan turun tiap tahunnya, dari tahun 2016 turun ,kenaikan terjadi pada tahun 2017 dan penurunan kembali terjadi pada tahun 2018. 


\section{UCAPAN TERIMA KASIH}

Penulis mengucapkan terima kasih kepada:

1. Kedua orang tua yang senantiasa merawat dan mndidik serta mncurahkan kasi sayang pada penulis.

2. Direkur AKBP beserta prodi AKBP serta bapak ibuk dosen yang telah mendidik dan mmberikan ilmu pngetahuan kepada penulis.

3. Pemimpin PT. BPR Cincin Permata Andalas cabang Padang yang telah mengizinkan penulis memperoleh informasi.

4. Kepada semua pihak yang telah membantu dalam membuat tugas akhir.

\section{DAFTAR PUSTAKA}

Irawati, \& Ningsih, F. (2020). Pengaruh Likuiditas dan Solvabilitas Terhadap Rentabilitas Ekonomis pada Koperasi Sawit Usaha Manunggal Desa Seresam Kecamatan Seberida Kabupaten Indragiri Hulu. J-MAS (Jurnal Manajemen Dan Sains), 5(1), 48. https://doi.org/10.33087/jmas.v5i1.147

Lestari, S. D., \& Fernos, J. (2015). Analisa Laporan Keuangan Berdasarkan Rasio Rentabilitas Pada Pt. Bpd Sumatera Barat. 1-10.

Handayani, M., \& Marlius, D. (2017). Analisis Tingkat Kesehatan PT. BPR Batang Kapas. https://doi.org/10.31227/osf.io/bq48z

Iswari, M., \& Fernos, J. (2019). Analisis Tingkat Kesehatan Bank Pada PT. Bank Pembangunan Daerah Sumatera Barat. https://doi.org/10.31227/osf.io/ja7ty

M. Taufiq, B. sufa. (2010). Pengaruh Penghimpunan Dana Terhadap Jumlah Kredit. 5(1976), 265-288.

Marlius, D., \& Sukma, J. (2020). Analisis Tingkat Kesehatan Bank Pt. Bank Perkreditan Rakyat Jorong Kampung Tangah Pariaman Cabang Padang. https://doi.org/10.31219/osf.io/dmjy5

Marlius, D., \& Mutia, M. (2020). Analisis Rasio Profitabilitas Pada Pt. Bank Pembangunan Daerah Sumatera Barat Cabang Pembantu Rsup Dr. M. Djamil Padang. https://doi.org/10.31219/osf.io/9nrc7

Marlius, D., \& Sukma, J. (2020). Analisis Tingkat Kesehatan Bank Pt. Bank Perkreditan Rakyat Jorong Kampung Tangah Pariaman Cabang Padang. https://doi.org/10.31219/osf.io/dmjy5

Murti, D. A. (2019). Analisis Faktor-Faktor Yang Mmempengaruhi Rentabilitas (ROA) Pada PT. BPR Di Kabupaten Semarang. 1, 1-476. https://doi.org/10.1017/CBO9781107415324.004

Putri, Y. A., \& Marlius, D. (2018). Analisis Tingkat Kesehatan Bank Pada PT. Bank Perkreditan Rakyat (BPR) Jorong Kampuang Tangah Pariaman Cabang Padang. https://doi.org/10.31227/osf.io/r98pv

Rahmayeli, D. S., \& Marlius, D. (2017). Analisis Kinerja Keuangan Pada PT. Bank Perkreditan Rakyat (BPR) Batang Kapas Pesisir Selatan. https://doi.org/10.31227/osf.io/sz5db

Sari, N. L. P. J., \& Sudiayani, N. N. (2007). Analisis Ratio Likuiditas, Solvabilitas, Rentabilitas, dan Manajemen Pada PT. BPR Puskusa Balidwipa Kecamatan Blahbatuh Gianyar. 826, 45-54. 
Sari, N., Nuringwahyu, S., \& Krisdianto, D. (2017). Analisis Rasio Likuiditas, Solvabilitas Dan Rentabilitas Untuk Melihat Kinerja Keuangan Bank. $135-153$.

Septiana, T. (2012). Analisis Rasio Solvabilitas Terhadap Laporan Keuangan Untuk Menilai Tingkat Kinerja Keuangan Perusahaan. 1-15.

Susanti, A. (2019). Analisis Likuiditas Dan Solvabilitas Untuk Memprediksikan Pfofitabilitas Pada PT. BPRS Artha Pamenang Kediri. 1, 1-476. https://doi.org/10.1017/CBO9781107415324.004 